\title{
Chip Fragmentation in the Milling of AZ91HP Magnesium Alloy
}

\author{
Jozef Kuczmaszewski ${ }^{1}$ - Ireneusz Zagorski1 ${ }^{1}$ - Olga Gziut ${ }^{1}$ - Stanislaw Legutko² - Grzegorz M. Krolczyk3,,* \\ ${ }^{1}$ Lublin University of Technology, Faculty of Mechanical Engineering, Poland \\ 2 Poznan University of Technology, Faculty of Mechanical Engineering and Management, Poland \\ 3 Opole University of Technology, Faculty of Mechanical Engineering, Poland
}

This paper presents new approaches to safety assessment in the milling of magnesium alloy. The objective of the study is to determine the effect of milling parameters and end mill geometry on machining safety, defined as the minimum probability of chip self-ignition. The assessment of safety and effectiveness in the milling of magnesium must include analysis of chip fractions formed during the milling process. The paper presents the state of the art of magnesium alloy machinability in terms of chip formation (chip fragmentation). Furthermore, the paper investigates the correlation between the quantity of distinguished chip fractions and variations in the parameters $v_{c}$ and $f_{z}$ as well as in the rake angle $\gamma_{o}$. In addition, the results of the dimensions of individual chip fractions are reported. The study was conducted on AZ91HP magnesium cast alloy, and the milling process was performed using carbide tools with varying rake angles $\left(\gamma_{o}=5^{\circ}\right.$ and $\left.\gamma_{o}=30^{\circ}\right)$. It has been found that chip fragmentation increases by increasing the above parameters, i.e. the feed rate $f_{z}$ and the cutting speed $v_{c}$. The observed chip fragmentation (the quantity of chip fractions) is lower at the tool rake angle $\gamma_{o}=30^{\circ}$. Finally, technological recommendations are formulated based on the quantity of chip fractions generated at particular settings. The results do not unequivocally demonstrate that chip dimensions increase or decrease by increasing the operational parameters of the milling process. In terms of their application, it is vital that machining processes be simultaneously effective and safe.

Keywords: high-speed dry milling, magnesium alloys, machinability, magnesium chips, end-mill geometry

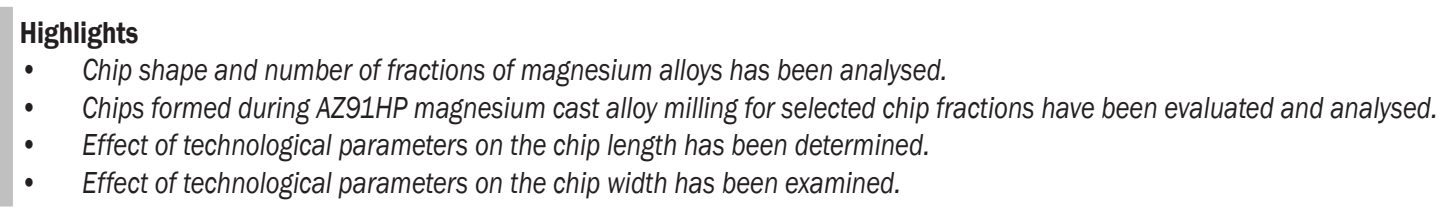

\section{INTRODUCTION}

Magnesium alloys are light metals that have attracted the interest of engineers in recent years [1] and [3]. Due to its low density, magnesium is widely used in the automotive and aerospace industry [4]. In addition to obvious advantages, such as low weight, the advantages of this metal included the wide availability of magnesium alloys [5] and good machining properties in comparison to other structural materials. However, chips formed during the machining of magnesium alloys might pose a serious threat and lead to uncontrollable ignition. The risk of magnesium ignition occurs when the temperature reaches 450 ${ }^{\circ} \mathrm{C}$, whereas the danger of imminent explosion occurs when magnesium particles (chips) of a size lower than $500 \mu \mathrm{m}$ are generated during the milling process [6]. In addition, magnesium alloys react with water to form magnesium oxide and hydrogen, which makes them potentially explosive [7]. It is, therefore, recommended to avoid the use of water-based cutting fluids in the machining of magnesium [8]. During the dry high-speed cutting of magnesium, thin and light chips are produced [9]. These kinds of chips are prone to cause ignition because of low heat capacity and high thermal expansion [10]. Moreover, dust chips forming during milling has a detrimental effect on machine elements such as bearings or guide ways; therefore, it is necessary to develop a milling technology which can ensure controlled chip fraction formation. At present, magnesium alloy machining is often done by modern high-speed machining technologies, such as HSM, HPC, and HSC. These technologies enable, among others, shorter machining time and lower production of non-deformed chips, which reduces the amount of heat transferred to the element being machined (heat generated in machining is removed with chips) [11]. In HSM, the tribological conditions influence the wear mechanisms, dramatically reducing tool life [12] and [13].

An important part of machining is the process of chip formation [14]. There are several factors essential for machining process safety, including temperature in the cutting area, quantity of chip fractions generated during milling, chip morphology, shape and mass of chips, thermal deformation, or heat marks on the surface of chips, ignition initiation analysis at low depths of cut, and the ignition point of a given type of $\mathrm{Mg}$ alloy. Due to practical reasons, surface roughness is often examined [15] and [16], both on the end face 
and lateral surface after end milling. Moreover, when producing innovative (biodegradable) elements made of magnesium alloys, e.g. from the Mg-Ca group [17], particular attention should be paid to the final quality of the machined surface. The improvement of surface quality is an important industrial task because it has direct influence on the performance and tribological properties of product [18] and [19]. Regarding changes in the cutting parameters such as cutting speed and depth of cut, the application of the PKD end mill produces a roughness parameter $R a$, which is equal to about $0.5 \mu \mathrm{m}$. Researchers have also investigated the cutting forces that are directly correlated with temperature in the cutting area.

Regarding the theoretical considerations (for the purposes of modelling the milling process), it is necessary to determine non-deformed chip thickness. The classical model of chip thickness assumes a cylindrical tool path. Li et al. [20] proposed a new approach to the determination of non-deformed chip thickness during milling. By analysis of the real trajectory of the end mill (trochoid tool path), a real momentary non-deformed chip thickness can be defined by solving the so-called deduced transcendental equation. Instead of a numerical method, it is possible to develop the function into a Taylor's series, which ensures higher accuracy compared to the traditional method. Errors (resulting from the application of the traditional method) are related with the number of end mill teeth, feed per tooth and machining tool diameter.

Saï et al. [21] proposed the modelling of nondeformed chip thickness with respect to end mill trajectory by circular (not linear, as previously) interpolation. During the circular trajectory of tool motion, chip thickness increases with a decrease in the radius of motion trajectory. This phenomenon can have both thermal and mechanical impact, which can, in turn, affect the roughness of the surface being machined.

The problems of non-deformed chip thickness, tool flank temperature, and partial melting of edges in $\mathrm{Mg}$ alloy chips were also investigated by Fang et al. [22]. They found that an increase in the cutting forces results in a higher thickness of deformed chips. When the non-deformed chip thickness decreases, the shear angle decreases too, leading to an increase in the temperature in the shear plane. The proposed method for measuring temperature (using k-type thermocouples) enables the measurement of the socalled "mean temperature of tool flank". Both in turning and milling, attempts were made to control chips in order to produce chips which are not easily flammable. The studies [23] and [24] report ignition in the milling of magnesium alloys (AM50A, AZ91D) at a very small depth of cut $a_{p}$, ranging from several $\mu \mathrm{m}$ to several hundred $\mu \mathrm{m}$. During these cutting tests, sparks, flares, and rings of fire were observed. Although the depth of cut of $1 \mu \mathrm{m}$ to $80 \mu \mathrm{m}$ applied in [25] is not generally used in the industry, the results provide significant insight into the problem. Chip ignition is hindered by increasing $\mathrm{Al}$ content, particularly when combined with an increase in small depths of cut and higher cutting speeds. Given that sparks or flares (hence, chip ignition) occur at lower cutting speeds and feed per tooth, ignition risk can be controlled by changing depth of cut, cutting speed and feed per tooth [26].

An interesting parameter connected with machining safety is the so-called ignition point of a given grade of magnesium alloy. Lin et al. [27] investigated the effect of cerium $(\mathrm{Ce})$ and aluminium (Al) on the ignition point and oxidation resistance of magnesium alloys. The highest ignition temperatures were, respectively, $535{ }^{\circ} \mathrm{C}$ for AM50 alloy and $525^{\circ} \mathrm{C}$ for AZ91D alloy for $0.25 \mathrm{wt} \%$ Ce. Zhou et al. [28] investigated the effect of $\mathrm{Ce}$ addition and the effect of particle (chip) size on the ignition point of $\mathrm{Mg}$ alloy AZ91D. It was found that the cerium content has a stronger impact on the ignition point than the particle size does. The content of Ce changed in the range $0.15 \mathrm{wt} . \%$ to $0.45 \mathrm{wt} . \%$. The particle size was $58 \mu \mathrm{m} 270 \mu \mathrm{m}$. The lowest ignition temperature (ignition point) was observed for $0.25 \mathrm{wt} . \%$ of Ce; it was about $525{ }^{\circ} \mathrm{C}$ for the particle size of about $150 \mu \mathrm{m}$. In contrast, according to Liu et al. [29], the ignition point for popular magnesium alloys: WE43, AZ31 and AZ91, is $644{ }^{\circ} \mathrm{C}$ for WE43, $628{ }^{\circ} \mathrm{C}$ for AZ31 and $600{ }^{\circ} \mathrm{C}$ for AZ91, respectively. However, the ignition temperature significantly depends on experimental details. Ravi Kumar et al. [30] also investigated the ignition resistance of pure $\mathrm{Mg}$ and its two alloys: AZ91 and WE43. The resistance to ignition (oxidation) depends on the presence of yttrium (Y), which affects the so-called ignition point. Ignition resistance depends on factors such as specimen geometry, as a large specimen surface can promote ignition. The specimens were subjected to induction heating, and the temperature was measured with a thermocouple. The ignition of WE43 alloy was not observed until $750{ }^{\circ} \mathrm{C}$. The ignition point of pure $\mathrm{Mg}$ was about $630^{\circ} \mathrm{C}$, while that of AZ91 alloy was about $580^{\circ} \mathrm{C}$ to $5900^{\circ} \mathrm{C}$.

The chips formed during milling can be classified according to the criteria established in the ISO 3685:1993 standard. This classification 
should, however, serve only as an example because the number of potential chip shapes is virtually infinite [31]. Chip fragmentation depends to a certain extent on each milling parameter. An undesirable impact of an increased quantity of intermediate chip fractions formed during milling can be observed at increasing $f_{z}$ and decreasing $a_{p}$, as well as under the conditions of excessive increase in the cutting speed $v_{c}$ [32]. Magnesium alloys can also be used as orthopaedic materials and biomaterials $(\mathrm{Mg}-\mathrm{Ca}$ alloys) for the production of implants. Clinical tests on the biocompatibility of $\mathrm{Mg}-\mathrm{Ca}$ alloys produced very interesting results. It was found that these alloys do not generate any toxic, carcinogenic, or mutagenic products, so they can be freely used from a physiological point of view. Salahshoor and Guo in [33] investigated the milling and burnishing of an $\mathrm{MgCa} 0.8$ alloy. They examined the effect of technological parameters on surface roughness, microhardness, microstructure and stresses after machining. Furthermore, the authors [17] investigated the formation of flank build-up (FBU), lamellas and (using the FEM method) chip temperature in milling. The temperature expected on the tool-chip contact surface can be close to the melting point $\left(\sim 650^{\circ} \mathrm{C}\right)$ for $\mathrm{MgCa} 0.8$ alloy. Magnesium alloys have a distinctive morphology, as they are of a lamellar structure on one side, while the other side of their surface is smooth and shiny due to chip-tool contact.

Aside from conventional machining methods, such as milling, it is often necessary to perform the finishing of part edges made of $\mathrm{Mg}$ and $\mathrm{Al}$ alloys, e.g. by wire brushing. Wire brushing parameters must be selected to ensure effective removal of burrs, formation of the required edge, and shaping of the required surface layer properties. The authors of the study [34] investigated the state of edges (corner radius) and surface roughness of the edges.
Factories producing parts for aircraft or car manufacturers constantly demand increased manufacturing effectiveness, which cannot be achieved without intensification of technological parameters of machining (predominantly $v_{c}$ and $f_{z}$ ). The production of the majority of such elements is aided by milling. Dynamic advances in the field of manufacturing and constant development of machinery, e.g. machine tools (machining centres) and cutting-edge machining tools, ensure high milling speed, high feed rate, and high-quality surface finish at the same time. Therefore, it appears vital to search for the most beneficial solutions which would provide excellent surface roughness and effectiveness, without compromising process safety. The key factors ensuring the safety in milling are: size, mass, shape, dimensions, and quantity of formed chips.

\section{METHODOLOGY, OBJECTIVE, AND SCOPE OF THE RESEARCH}

This study predominantly consists of an analysis of selected technological parameters, $v_{c}$ and $f_{z}$, and effect on the risk of chip ignition as defined by the analysed indicators. Establishing a suitable relation between the parameters in question is of paramount importance towards attaining superior effectiveness and safety of the machining process. The secondary objective of the study is to analyse chip fractions formed during the milling of magnesium alloys. Fig. 1 shows a plan of the experiments performed by tools of varying cutting-edge geometry (different tool rake angle $\gamma_{o}$ ).

A schematic diagram of the experimental set-up is shown in Fig. 2a. The main aim of the experiment was to determine safe yet effective technological parameters of a down-milling process. Fig. $2 b$ shows an example image of a chip with its dimensions. These dimensions are, in fact, orthogonal projections

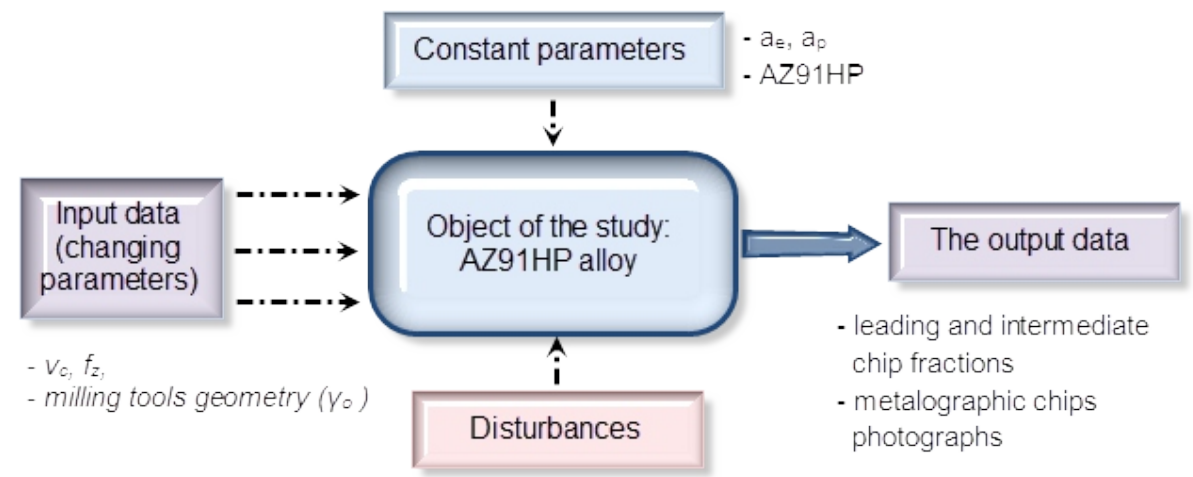

Fig. 1. Design of the experiment for determination of impact of $v_{c}, f_{z}$, and $\gamma_{o}$ on chip form 

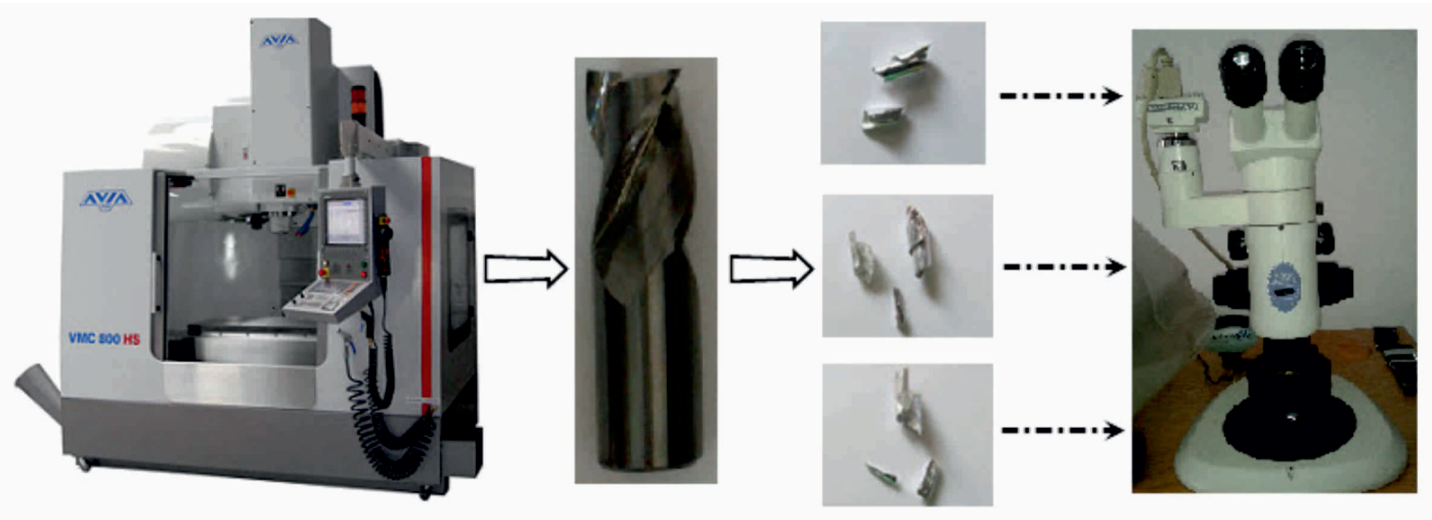

a)

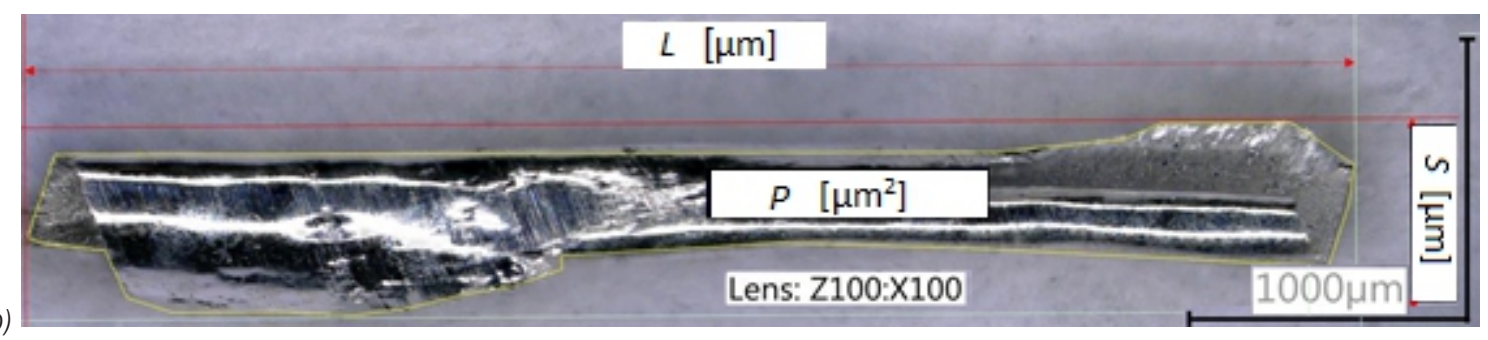

Fig. 2. Schematic diagram of the: a) experimental set-up, b) chip dimensions

Table 1. Cutting conditions in the experiment

\begin{tabular}{|c|c|c|c|c|c|c|c|}
\hline No & $f_{z}[\mathrm{~mm} / \mathrm{tooth}]$ & $v_{c}[\mathrm{~m} / \mathrm{min}]$ & $n$ [rev/min] & $v_{f}[\mathrm{~mm} / \mathrm{min}]$ & $a_{p}[\mathrm{~mm}]$ & $z$ & $a_{e}[\mathrm{~mm}]$ \\
\hline 1 & & 400 & 7958 & 3581 & \multirow{6}{*}{6} & \multirow{6}{*}{3} & \multirow{6}{*}{14} \\
\hline 2 & 0.15 & 800 & 15915 & 7162 & & & \\
\hline 3 & & 1200 & 23873 & 10743 & & & \\
\hline 4 & 0.05 & \multirow{3}{*}{800} & \multirow{3}{*}{15915} & 2387 & & & \\
\hline 5 & 0.15 & & & 7162 & & & \\
\hline 6 & 0.3 & & & 14324 & & & \\
\hline
\end{tabular}

a)

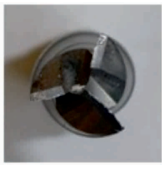

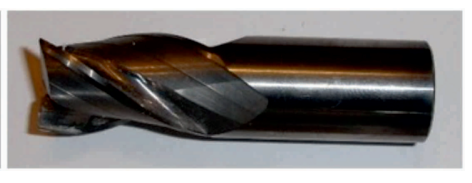

Fig. 3. Three-tooth carbide end mill described by angle: a) $y_{0}=5^{\circ}$, b) $y_{0}=30^{\circ}$

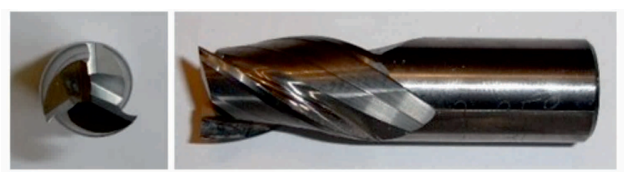

of the chip onto the plane. To simplify the description, however, hereinafter the following terms are used: chip length $\mathrm{L}$, chip width $\mathrm{S}$ and chip area $\mathrm{P}$.

The research was performed on an Avia VMC800HS vertical machining centre. The following constant cutting conditions were applied: radial depth of cut $a_{e}=14 \mathrm{~mm}$, axial depth of cut $a_{p}=6 \mathrm{~mm}$. The variable technological parameters of the milling process examined in the study included: $f_{z}=0.05 \mathrm{~mm} /$ tooth to $0.3 \mathrm{~mm} /$ tooth, $v_{c}=400 \mathrm{~m} / \mathrm{min}$ to $1200 \mathrm{~m} / \mathrm{min}$, and the rake angle $\gamma_{o}=5^{\circ}$ to $30^{\circ}$. Table
1 lists the ranges of parameters applied during the milling of AZ91HP.

For the purpose of description, the following definitions are applied:

- fraction - a population of elements of a particular size or dimensions,

- fragmentation - formation of an intermediate chip fraction of different shape and mass during machining, alongside the leading (prevailing and characteristic) fraction.

The tests were conducted on AZ91HP magnesium cast alloy. Carbide tools with varying rake angles are 
shown in Fig. 3. The tool used was a $16 \mathrm{~mm}$ carbide end mill.

The tests were conducted for the above technological parameters of milling. The division into the leading and intermediate fractions was based on the shape and size of chips, Fraction A being the biggest and Fraction D the smallest. The term "leading fraction" was ascribed to Fraction A, while smaller fractions were referred to as 'intermediate fractions'. Furthermore, the tests provided information about the percentage of a particular chip fraction at different cutting speeds $v_{c}$ and feed rates $f_{z}$. The point of reference for the chip fraction division was provided by the Polish Standard PN ISO 3685:1996, which is a classification originally referring to the turning of steel.

The first step of chip fraction division involved selecting a leading fraction based on chip shape. The leading fraction had the highest unit mass and was the most representative in terms of quantity. Next, other intermediate chip fractions were selected (also based on their shape). Moreover, the intermediate fraction was defined in two ways: as a fraction with a different shape (compared to that of the leading fraction or the preceding intermediate fraction) and as a fraction with a lower mass (in most cases) by about $50 \%$ of that of the leading fraction or the preceding intermediate chip fraction.

\section{RESULTS AND DISCUSSION}

Table 2 shows the impact of the cutting speed $v_{c}$ on the form of chips and the quantity of chip fractions distinguished in set conditions at the cutting tool rake angle $\gamma_{o}=5^{\circ}$. At the cutting speed $v_{c}=400 \mathrm{~m} / \mathrm{min}$, two chip fractions were determined, whereas three fractions can be observed at the speeds of $v_{c}=800$ $\mathrm{m} / \mathrm{min}$ and $v_{c}=1200 \mathrm{~m} / \mathrm{min}$. The shape of chips categorized as Fraction B (cutting speed $v_{c}=400 \mathrm{~m} / \mathrm{min}$ ) was described as loose arc, and Fraction A chips were described as short conical helical and, similarly to Fraction A, they were produced at $v_{c}=800 \mathrm{~m} / \mathrm{min}$. Fractions $\mathrm{B}$ and $\mathrm{C}$ consisted of loose arc chips, however, in the case of Fraction $\mathrm{C}$ the chips were tighter, which was not the only difference, as they also differed in terms of the size. At the cutting speed $v_{c}=1200 \mathrm{~m} / \mathrm{min}$, loose arc chips were observed (Fraction $\mathrm{B}$ and $\mathrm{C}$ ) along with short tight tubular chips.

Fig. 4 shows the percentage of particular chip fractions at different cutting speeds.

At the lowest cutting speed, two chip fractions were distinguished, with A being the leading one with a $79 \%$ share of the total percentage of chips. In the case of the two other cutting speed values, A was also the leading fraction, containing the largest chips. The percentage of smaller fractions in the examined cases was also similar. Fraction B (arc chips), which amounted to $21 \%$ at $v_{c}=400 \mathrm{~m} / \mathrm{min}$ and increase

Table 2. Impact of cutting speed on chip shape and quantity of fractions (AZ91HP magnesium cast alloy):

a) $v_{c}=400 \mathrm{~m} / \mathrm{min}$, b) $v_{c}=800 \mathrm{~m} / \mathrm{min}$, c) $v_{c}=1200 \mathrm{~m} / \mathrm{min}$, at $f_{z}=0.15 \mathrm{~mm} /$ tooth, $a_{p}=6 \mathrm{~mm}$ and $y_{0}=5^{\circ}$

a) $v_{c}=400 \mathrm{~m} / \mathrm{min}$




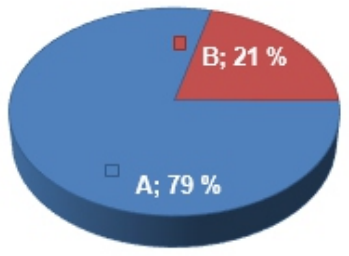

$\square \mathrm{A} \square \mathrm{B}$

a)

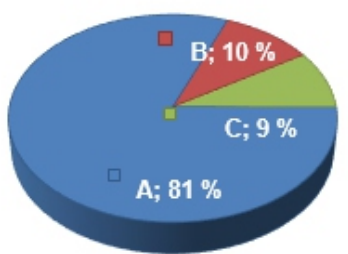

$\square \mathrm{A} \square \mathrm{B} \square \mathrm{C}$

b)

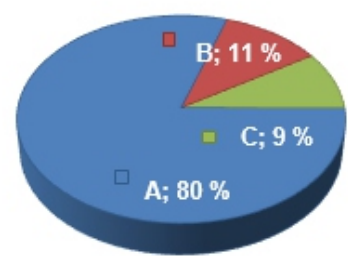

$\square \mathrm{A} \square \mathrm{B} \square \mathrm{C}$

c)

Fig. 4. Percentage of particular chip fractions versus cutting speed in the milling of AZ91HP magnesium alloy at carbide tool rake angle $\gamma_{0}=5^{\circ}$
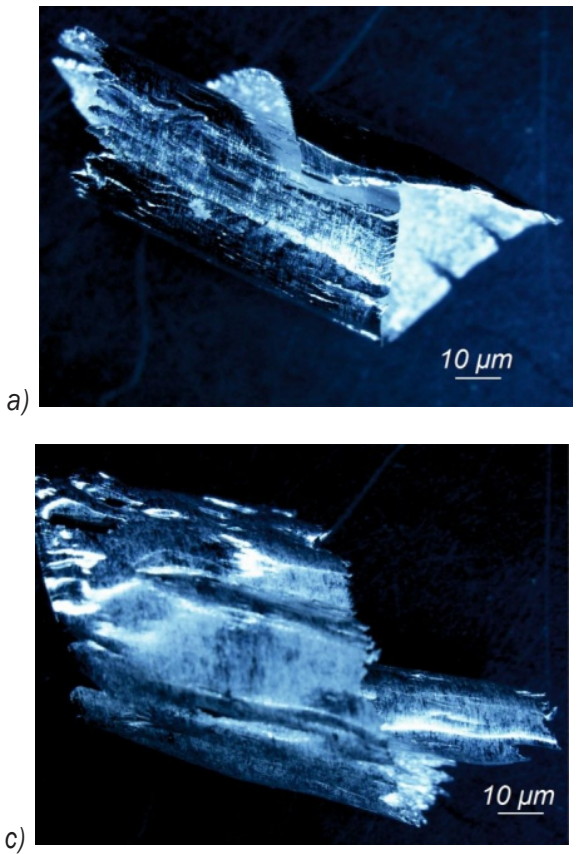
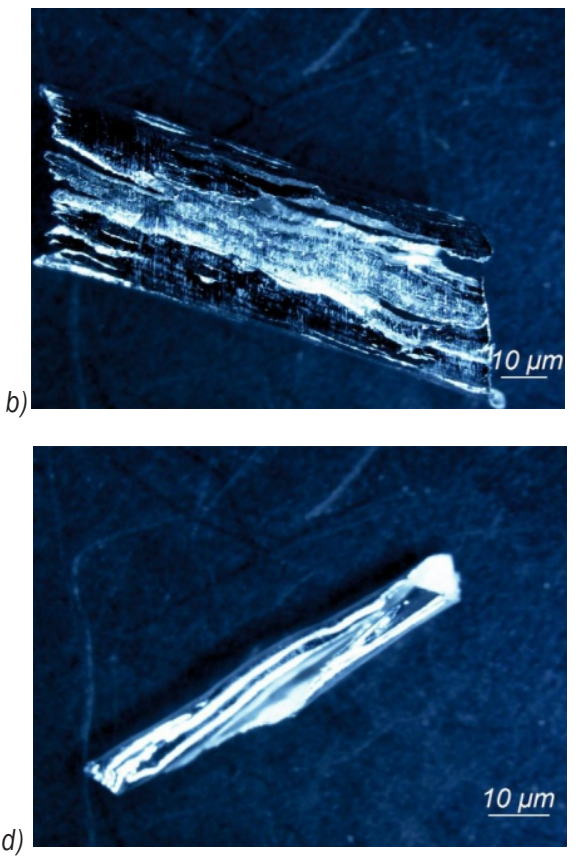

Fig. 5. Chips formed during AZ91HP magnesium cast alloy milling for selected chip fractions and different cutting speeds $v_{c}$ : a) $v_{c}=400 \mathrm{~m} / \mathrm{min}$, Fraction A, b) $v_{c}=400 \mathrm{~m} / \mathrm{min}$, Fraction B, c) $v_{c}=1200 \mathrm{~m} / \mathrm{min}$, Fraction A, d) $v_{c}=1200 \mathrm{~m} / \mathrm{min}$, Fraction C

in speed to $v_{c}=800 \mathrm{~m} / \mathrm{min}$, was divided into two fractions: $\mathrm{B}$ and $\mathrm{C}$ (both consisting of arc chips, however of different sizes), amounting to the total of $19 \%$. A similar distinction could be observed at $v_{c}=$ $1200 \mathrm{~m} / \mathrm{min}$.

Fig. 5 shows chip shapes formed during milling performed at different cutting speeds $v_{c}$.

Fig. 5 shows chips classified as the smallest and largest fractions obtained at limit cutting speeds. The chips in question should generally be referred to as segmented, mainly due to the discontinuous character of the milling process. It should be noted that with increasing the cutting speed $v_{c}$, the quality of the outer surface of the chip (which became rough) decreased. In the case of small fractions, the chips became tighter with increasing speed, and the cutting speed $v_{c}=400$ $\mathrm{m} / \mathrm{min}$ produced arc chips. An opposite effect was observed in the case of larger chips, which tend to have a tighter helix when the cutting speed is lower, $v_{c}=400 \mathrm{~m} / \mathrm{min}$. In addition, built-up edges in the formed chips were observed. The distinguished chip forms are desirable from the point of view of chip removal from the working space.

Table 3 provides information about the effect of the feed rate $f_{z}$ on the chip form and the quantity of chip fractions observed in the tests at given parameters. The lowest value of the feed tooth resulted in Fraction A dominating other chip forms. Leading fraction chips were described as short conical helical. Another fraction distinguished at these settings comprised chips of a distinctly different size and shape (short, tight and tubular). At the feed per tooth of $f_{z}=0.15$ $\mathrm{mm} /$ tooth the following chips forms were singled out: Fraction A - short conical helical chips, B - arc loose 
Table 3. Impact of cutting speed on chip shape and quantity of fractions (AZ91HP magnesium cast alloy): a) $f_{z}=0.05 \mathrm{~mm} /$ tooth, b) $f_{z}=0.15 \mathrm{~mm} /$ tooth, c) $f_{z}=0.3 \mathrm{~mm} /$ tooth, at $v_{c}=800 \mathrm{~m} / \mathrm{min}, a_{p}=6 \mathrm{~mm}$ and $\gamma_{o}=5^{\circ}$

a) $f_{z}=0.05 \mathrm{~mm} /$ tooth

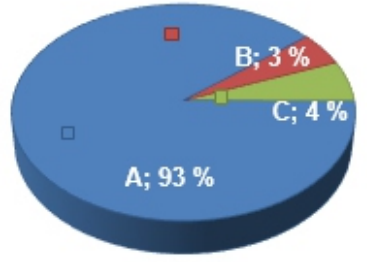

$\square \mathrm{A} \square \mathrm{B} \square \mathrm{C}$

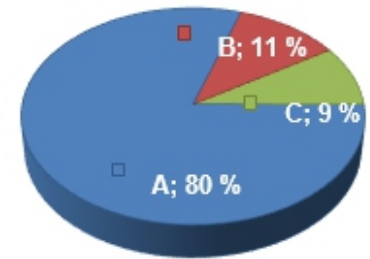

$\square \mathrm{A} \square \square \mathrm{C}$

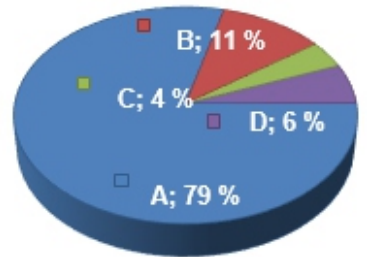

$\square \mathrm{A} \square \mathrm{B} \square \mathrm{C} \square \mathrm{D}$

Fig. 6. Percentage of particular chip fractions versus feed per tooth in the milling of AZ91HP magnesium alloy at carbide tool rake angle $\gamma_{0}=5^{\circ}$, a) $f_{z}=0.05 \mathrm{~mm} /$ tooth, b) $f_{z}=0.15 \mathrm{~mm} /$ tooth, and c) $f_{z}=0.3 \mathrm{~mm} /$ tooth

chips (bigger), $\mathrm{C}-$ loose arc chips (smaller). Finally, at the feed per tooth $f_{z}=0.3 \mathrm{~mm} /$ tooth the following chip fractions were distinguished: A - short conical helical chips, $\mathrm{B}$ and $\mathrm{C}$ - loose arc chips, D - needle chips.

Fig. 6 shows the percentage of particular chip fractions at different rates of feed per tooth $f_{z}$.

At the feed per tooth $f_{z}=0.05 \mathrm{~mm} /$ tooth, three fractions were distinguished, the leading one being Fraction A, accounting for $97 \%$ of the total percentage of chips. An increase in this parameter produced a higher number of observed fractions, e.g. at $f_{z}=0.3$ $\mathrm{mm} /$ tooth four chip fractions could be distinguished. In both cases, the percentage of the leading fraction was approximately $80 \%$.

Fig. 7 shows chip shapes formed during milling performed at different feed per tooth rates; it also shows chips obtained from the smallest and largest fractions at the limit feed per tooth value $f_{z}$. When comparing the leading fractions produced at different feed per tooth values, it can be observed that at $f_{z}=0.05 \mathrm{~mm} /$ tooth, the outer surface of the chip is quite frayed (numerous small dents). Increasing the value of the feed per tooth results in increasing smoothness of the surface. A similar observation was made in the case of the smallest fractions: the outer surface is rougher at $f_{z}=0.05 \mathrm{~mm} /$ tooth. The shape of chips of the leading fraction formed when the feed per tooth value was changed is advantageous for transport and storage.

Table 4 shows the impact of the cutting speed on the form of chips and the number of fractions distinguished during milling with the tool rake angle $\gamma_{\mathrm{o}}=30^{\circ}$. Fraction A chips (produced at $v_{c}=400 \mathrm{~m} / \mathrm{min}$ ) are described as short conical helical and Fraction B chips as loose arc. A similar distinction was made 

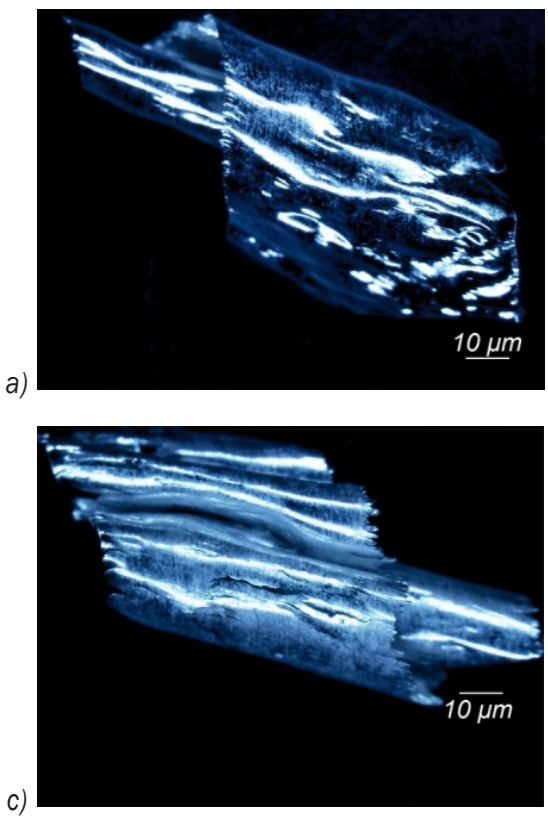

b)
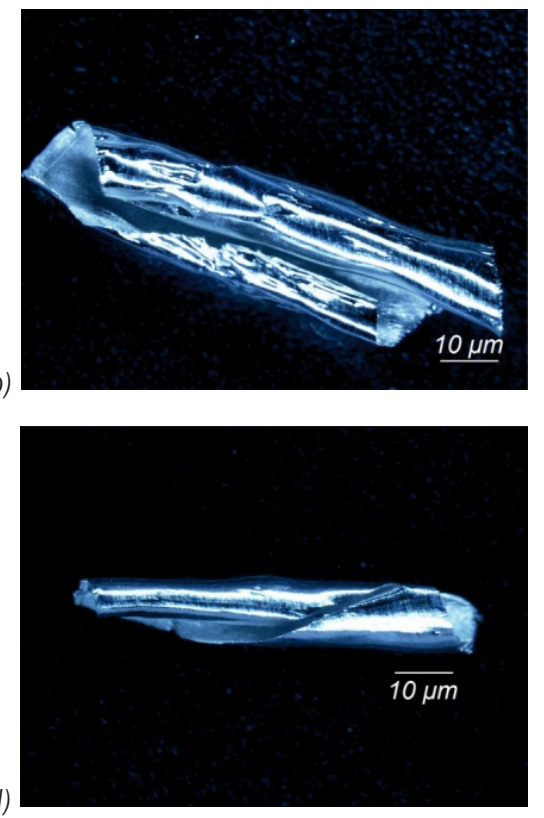

Fig. 7. Chips formed during AZ91HP magnesium cast alloy milling for selected chip fractions and different feed per tooth $f_{z}$ : a) $f_{z}=0.05 \mathrm{~mm} /$ tooth, fraction $A$ b) $f_{z}=0.05 \mathrm{~mm} /$ tooth, fraction $B$ c) $f_{z}=0.3 \mathrm{~mm} /$ tooth, fraction $A$, d) $f_{z}=0.05 \mathrm{~mm} /$ tooth, fraction $D$

Table 4. Impact of cutting speed on chip shape and quantity of fractions (AZ91HP magnesium cast alloy): a) $v_{c}=400 \mathrm{~m} / \mathrm{min}$, b) $\left.v_{c}=800 \mathrm{~m} / \mathrm{min}, \mathrm{c}\right) v_{c}=1200 \mathrm{~m} / \mathrm{min}$, at $f_{z}=0.15 \mathrm{~mm} /$ tooth, $a_{p}=6 \mathrm{~mm}$ and $\gamma_{o}=30^{\circ}$

\begin{tabular}{|c|c|c|c|c|c|}
\hline Fraction & All fractions & $\begin{array}{l}\text { Leading } \\
\text { fraction A }\end{array}$ & $\begin{array}{l}\text { Intermediate } \\
\text { fraction B }\end{array}$ & $\begin{array}{l}\text { Intermediate } \\
\text { fraction C }\end{array}$ & $\begin{array}{c}\text { Intermediate } \\
\text { fraction D }\end{array}$ \\
\hline a) $v_{c}=400 \mathrm{~m} / \mathrm{min}$ & & & & $\begin{array}{c}\text { no fraction } \\
\text { detected }\end{array}$ & $\begin{array}{c}\text { no fraction } \\
\text { detected }\end{array}$ \\
\hline b) $v_{c}=800 \mathrm{~m} / \mathrm{min}$ & & & & $\begin{array}{c}\text { no fraction } \\
\text { detected }\end{array}$ & $\begin{array}{l}\text { no fraction } \\
\text { detected }\end{array}$ \\
\hline c) $v_{c}=1200 \mathrm{~m} / \mathrm{min}$ & & & 1 & $\begin{array}{l}\text { no fraction } \\
\text { detected }\end{array}$ & $\begin{array}{c}\text { no fraction } \\
\text { detected }\end{array}$ \\
\hline
\end{tabular}

for the speed $v_{c}=800 \mathrm{~m} / \mathrm{min}$. At the speed $v_{c}=1200$ $\mathrm{m} / \mathrm{min}$, Fraction A consisted of short conical helical chips, whereas needle chips could be observed in Fraction B.

Fig. 8 shows the percentage of particular chip fractions versus cutting speed in the milling of AZ91HP magnesium alloy.
As can be seen in Fig. 8, two fractions are determined per each cutting speed, and the percentage of particular chip fractions is virtually identical as at $v_{c}=400$ and $v_{c}=800 \mathrm{~m} / \mathrm{min}$. At the speed $v_{c}=1200$ $\mathrm{m} / \mathrm{min}$, A remained the leading fraction; however, a distinct decrease in the number of chips belonging to Fraction B can be observed. 


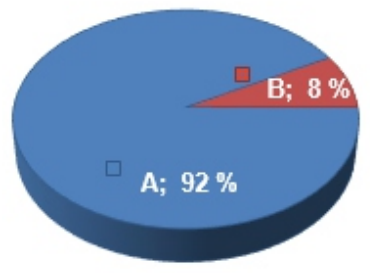

$\square \mathrm{A} \square \mathrm{B}$

a)

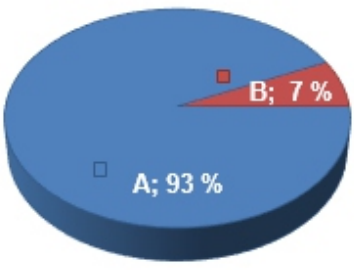

$\square \mathrm{A} \square \mathrm{B}$

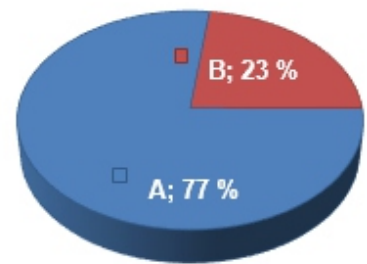

$\square \mathrm{A} \square \mathrm{B}$

c)

Fig. 8. Percentage of particular chip fractions versus cutting speed in the milling of AZ91HP magnesium alloy at carbide tool rake angle $\gamma_{o}=30^{\circ}$

a)

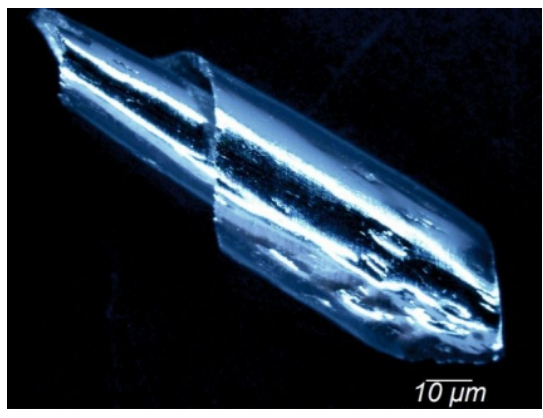

c)

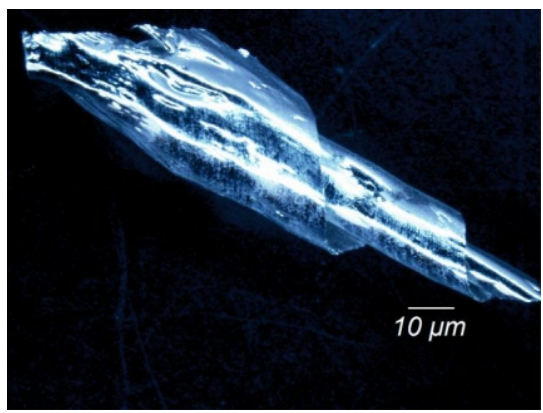

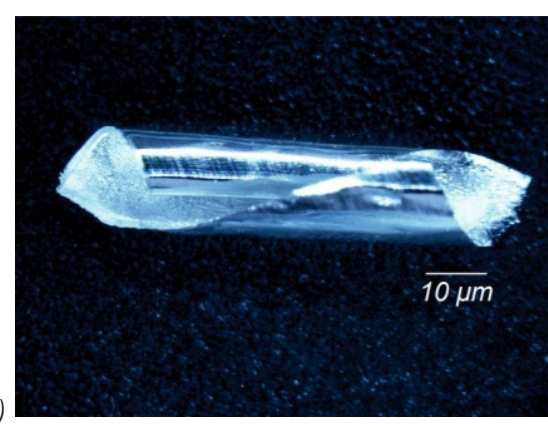

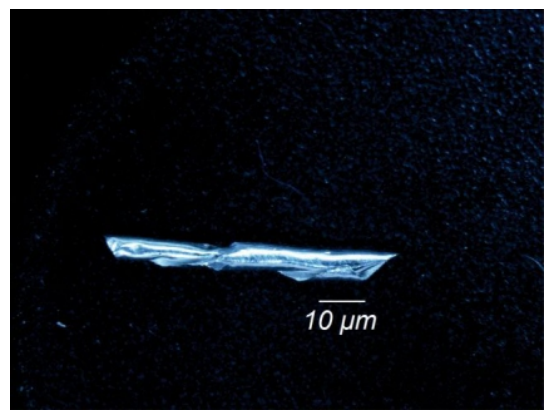

Fig. 9. Chips formed during AZ91HP magnesium cast alloy milling for selected chip fractions and different cutting speeds $v_{c}$ : a) $v_{c}=400 \mathrm{~m} / \mathrm{min}$, Fraction A, b) $v_{c}=400 \mathrm{~m} / \mathrm{min}$, Fraction B, c) $v_{c}=1200 \mathrm{~m} / \mathrm{min}$, Fraction A, d) $v_{c}=1200 \mathrm{~m} / \mathrm{min}$, Fraction $B$

Fig. 9 shows chip shapes observed during the milling process performed at different cutting speeds $v_{c}$ at the tool rake angle $\gamma_{o}=30^{\circ}$.

Fig. 9 shows the chips of the smallest and the biggest fractions, distinguished at the limit cutting speeds $\left(v_{c}=400 \mathrm{~m} / \mathrm{min}\right.$ and $\left.v_{c}=1200 \mathrm{~m} / \mathrm{min}\right)$. The representative chips can be described as segmented. With an increase in the cutting speed $v_{c}$, a tighter helix can be noted, as demonstrated by Fraction B (Figs. $7 \mathrm{~b}$ and $\mathrm{d})$. The outer surface of the chips is shiny and smooth when machined at a slower speed. The edges of the chips formed at the tool rake angle $\gamma_{o}=30^{\circ}$ are less built-up than those of the chips machined at the tool rake angle $\gamma_{o}=5^{\circ}$.
The photographs in Table 5 show the variations in chip form and the quantity of chip fractions versus the feed tooth $f_{z}$. The shape of the chips formed when only the feed rate was changed does not reveal any great differences. One can predominantly observe short conical helical chips (Fractions A and $\mathrm{B}$ at $f_{z}=0.05$ $\mathrm{mm} /$ tooth, Fractions $\mathrm{A}$ and $\mathrm{B}$ at $f_{z}=0.15 \mathrm{~mm} /$ tooth and Fraction $\mathrm{A}$ at $f_{z}=0.3 \mathrm{~mm} /$ tooth). However, the greatest difference can be observed with respect to chip size. In Fractions C (the slowest feed) and B (the fastest feed), needle chips can be distinguished.

Fig. 10 shows the percentage of particular chip fractions at different rates of feed per tooth $f_{z}$.

The number of fractions was the highest at the lowest feed per tooth value, and in the remaining 
Table 5. Impact of cutting speed on chip shape and quantity of fractions (AZ91HP magnesium cast alloy):

a) $f_{z}=0.05 \mathrm{~mm} /$ tooth, b) $f_{z}=0.15 \mathrm{~mm} /$ tooth, c) $f_{z}=0.3 \mathrm{~mm} /$ tooth, at $v_{c}=800 \mathrm{~m} / \mathrm{min}, a_{p}=6 \mathrm{~mm}$ and $\gamma_{o}=30^{\circ}$

\begin{tabular}{|c|c|c|c|c|c|}
\hline$f_{z}[\mathrm{~mm} /$ tooth $]$ & All fractions & $\begin{array}{l}\text { Leading } \\
\text { fraction A }\end{array}$ & $\begin{array}{c}\text { Intermediate } \\
\text { fraction B }\end{array}$ & $\begin{array}{l}\text { Intermediate } \\
\text { fraction C }\end{array}$ & $\begin{array}{l}\text { Intermediate } \\
\text { fraction D }\end{array}$ \\
\hline a) $f_{z}=0.05 \mathrm{~mm} /$ tooth & & & & 1 & $\begin{array}{c}\text { no fraction } \\
\text { detected }\end{array}$ \\
\hline b) $f_{z}=0.15 \mathrm{~mm} /$ tooth & & & p & $\begin{array}{l}\text { no fraction } \\
\text { detected }\end{array}$ & $\begin{array}{c}\text { no fraction } \\
\text { detected }\end{array}$ \\
\hline b) $f_{z}=0.3 \mathrm{~mm} /$ tooth & & & 1 & $\begin{array}{l}\text { no fraction } \\
\text { detected }\end{array}$ & $\begin{array}{l}\text { no fraction } \\
\text { detected }\end{array}$ \\
\hline
\end{tabular}

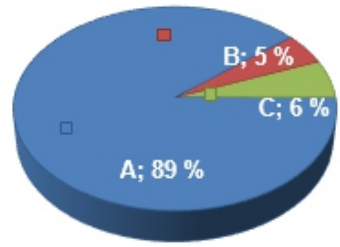

$\square \mathrm{A} \square \mathrm{B} \square \mathrm{C}$

a)

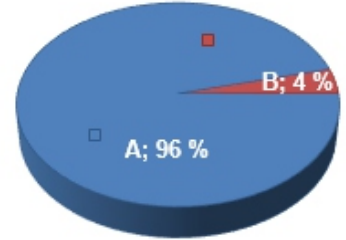

$\square \mathrm{A} \square \mathrm{B}$

b)

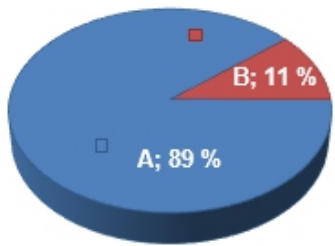

$\square \mathrm{A} \square \mathrm{B}$

c)

Fig. 10. Percentage of particular chip fractions versus feed per tooth in the milling of AZ91HP magnesium alloy at carbide tool rake angle $\gamma_{o}=30^{\circ}$

cases two fractions were noted. Out of three fractions distinguished at $f_{z}=0.05 \mathrm{~mm} /$ tooth, Fraction $\mathrm{A}$ is the most numerous, while the percentages of Fractions B and $\mathrm{C}$ are comparable. At $f_{z}=0.15 \mathrm{~mm} /$ tooth, Fraction $\mathrm{A}$ is the leading one (96\%), whereas the share of $\mathrm{B}$ is insignificant. Needle chips (Fraction B) constituted mere $11 \%$, and Fraction A remains the leading fraction at $f_{z}=0.3 \mathrm{~mm} /$ tooth.

Fig. 11 shows chip shapes formed during milling performed at different values of feed per tooth $f_{z}$.

Fig. 11 show chips of the smallest and largest fractions produced at the limit feed values $\left(f_{z}=0.05\right.$ $\mathrm{mm} /$ tooth and $f_{z}=0.3 \mathrm{~mm} /$ tooth). The outer surface of the chips changed from wavy (Figs. 11a and $b$ ) to smooth (Figs. 11c and d).

The technological factors which contributed to reducing chip fragmentation to a minimum were cutting speed and feed tooth; in addition, it was observed that the rake angle $\gamma_{o}=30^{\circ}$ led to limiting the number of chip fractions. Moreover, the characteristic dimensions of the produced chips, including chip length L, chip width $\mathrm{S}$ and chip surface area $\mathrm{P}$, were examined.

Fig. 12 illustrates the effect of the cutting speed $v_{c}$ and the feed per tooth $f_{z}$ on the length of the chip, both in the leading and intermediate chip fractions. An increase in the parameters $v_{c}$ and $f_{z}$ does not have an unequivocal effect on increasing or decreasing the length, width or surface area of chips. A more detailed analysis of the effect of the above parameters is feasible only for chip fractions, which occur at all values of $v_{c}$ and $f_{z}$.

Fig. 13 illustrates the effect of the cutting speed $v_{c}$ and the feed per tooth $f_{z}$ on chip width.

Fig. 14 illustrates the effect of the cutting speed $v_{c}$ and the feed per tooth $f_{z}$ on chip area.

The examination of the dimensions of chips produced by milling using tools with a varying rake angle $\gamma_{o}$ allow us to make the following observations with respect to the leading fraction: 

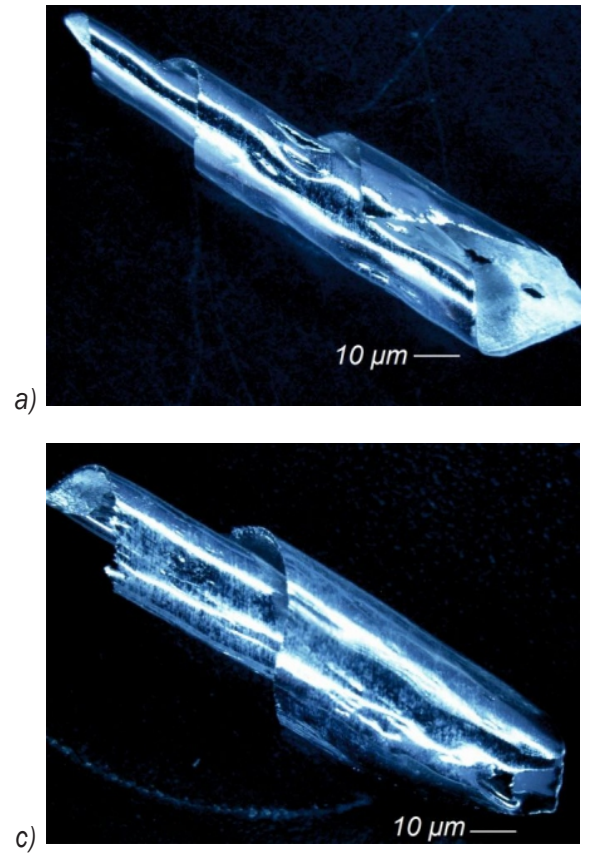
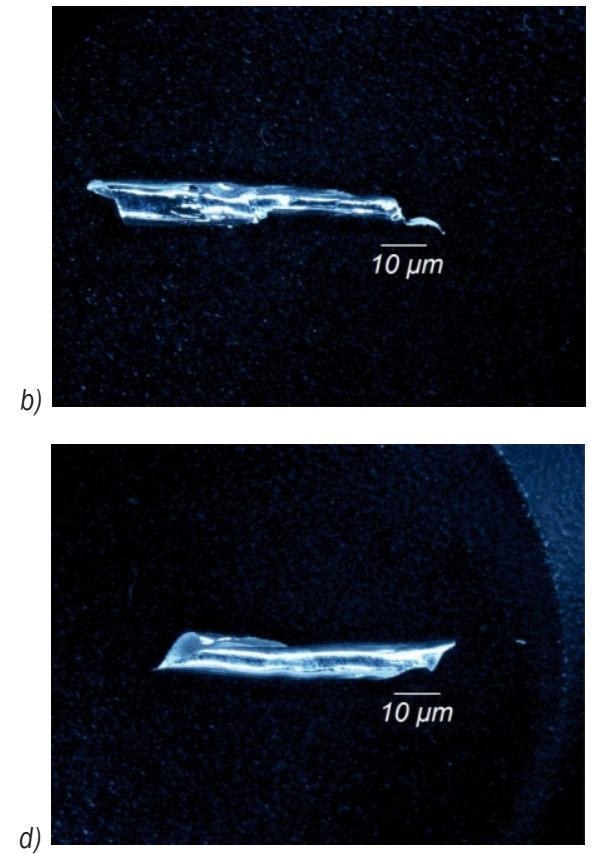

for selected chip fractions and different values of feed per tooth $f_{z}$ : a) $f_{z}=0.05 \mathrm{~mm} /$ tooth, Fraction $A$ b) $f_{z}=0.05 \mathrm{~mm} /$ tooth, Fraction C, c) $f_{z}=0.3 \mathrm{~mm} /$ tooth, Fraction A, d) $f_{z}=0.3 \mathrm{~mm} /$ tooth, Fraction $B$

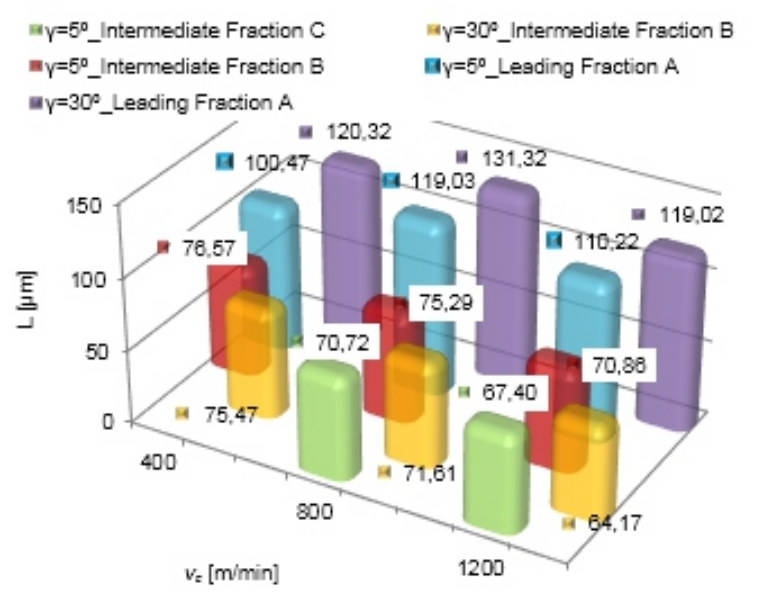

a)

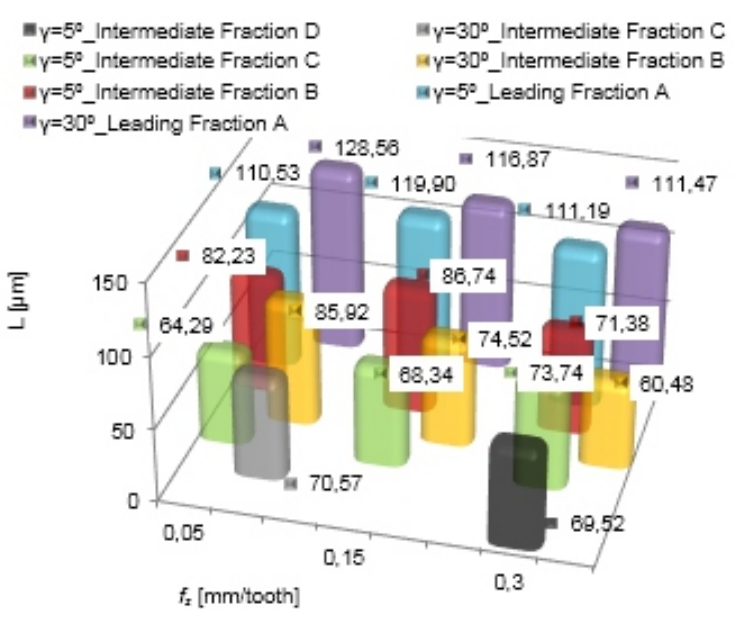

b)

Fig. 12. Effect of technological parameters on chip length $L:$ a) $v_{c}$, b) $f_{z}$

- on changing $v_{c}$, the chip length $\mathrm{L}$ first increases and then decreases, both at $\gamma_{o}=5^{\circ}$ and $\gamma_{o}=30^{\circ}$,

- on changing $f_{z}$, the chip length $\mathrm{L}$ first increases and then decreases at $\gamma_{o}=5^{\circ}$ and decreases in the entire range of change in the feed per tooth $f_{z}$ at $\gamma_{o}$ $=30^{\circ}$,

- on changing $v_{c}$, the chip width $\mathrm{S}$ first decreases and then increases, both at $\gamma_{o}=5^{\circ}$ and $\gamma_{o}=30^{\circ}$,

- on changing $f_{z}$, the chip width $\mathrm{S}$ first slightly decreases and then remains stable at $\gamma_{o}=5^{\circ}$ and increases at $\gamma_{o}=30^{\circ}$,
- on changing $v_{c}$, the chip surface area $\mathrm{P}$ increases at $\gamma_{o}=5^{\circ}$ and decreases at $\gamma_{o}=30^{\circ}$,

- on changing $f_{z}$, the chip surface area first increases and then increases at $\gamma_{o}=5^{\circ}$ ) and increases at $\gamma_{o}=$ $30^{\circ}$ ).

We did not observe an unequivocal tendency for an increase or decrease in the dimensions of the leading chip fraction with increasing the cutting speed $v_{c}$ and feed per tooth $f_{z}$.

A detailed analysis of the intermediate fraction can only be done provided that this fraction occurs in 


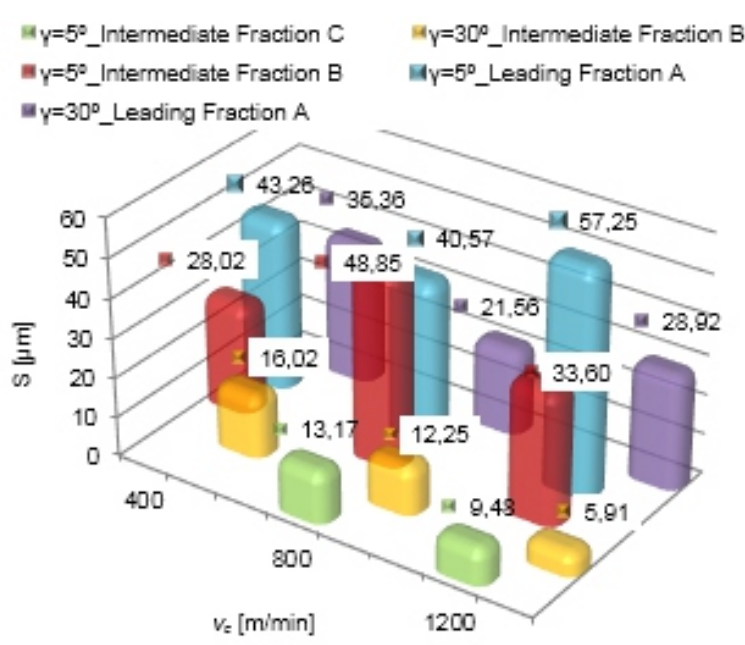

a)

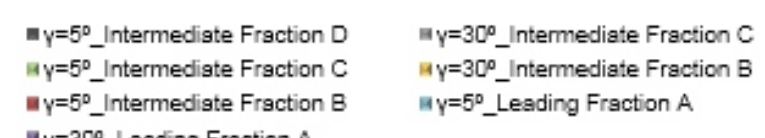

$\mathbf{a}=30^{\circ}$ Legding Fraction $\mathrm{A}$

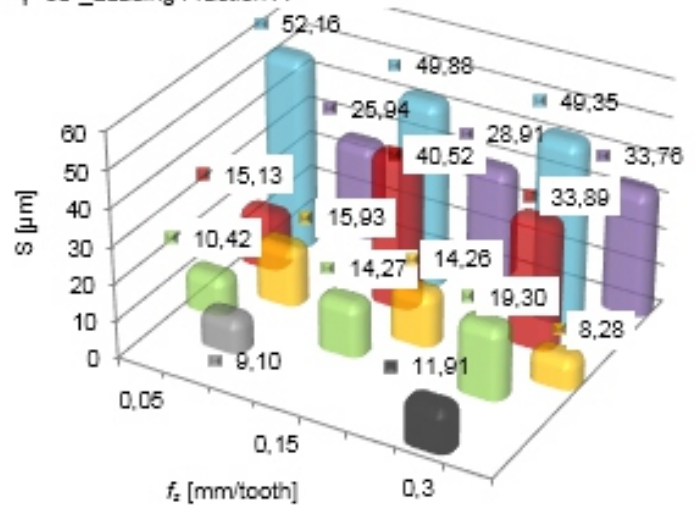

b)

Fig. 13. Effect of technological parameters on chip width S: a) $v_{c}$, b) $f_{z}$

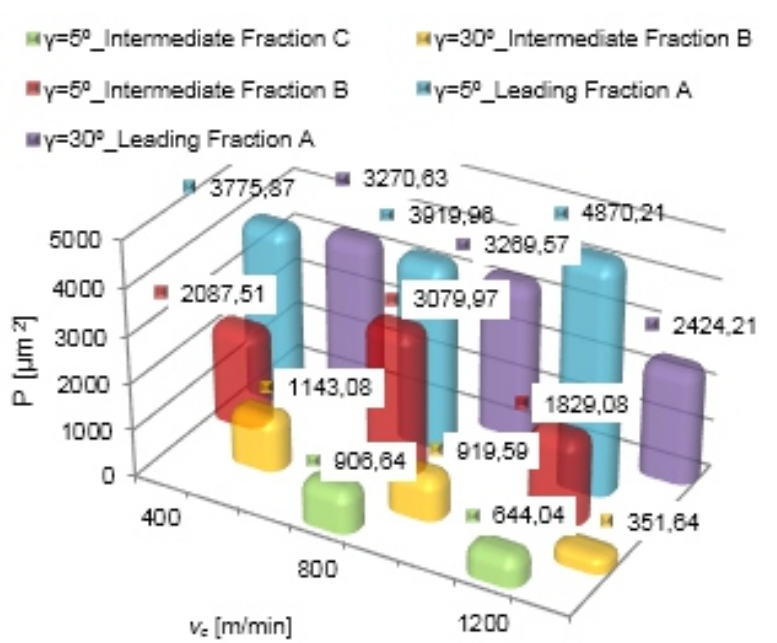

a)
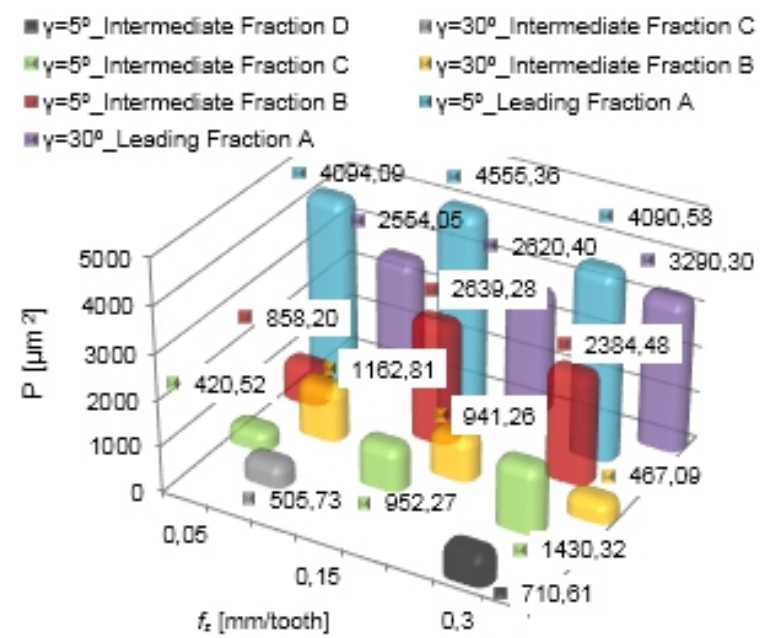

b)

Fig. 14. Effect of technological parameters on chip area P: a) $v_{c}$, b) $f_{z}$

the entire range of the investigated milling variables.

This occurs for:

- on changing $v_{c}$, the chip length $\mathrm{L}$ of intermediate Fraction B decreases both at $\gamma_{o}=5^{\circ}$ and $\gamma_{o}=30^{\circ}$,

- on changing $f_{z}$ in intermediate Fraction B $\left(\gamma_{o}=\right.$ $5^{\circ}$ and $\left.\gamma_{o}=30^{\circ}\right)$ and intermediate Fraction $\mathbf{C}\left(\gamma_{o}\right.$ $=5^{\circ}$ ), the following trends can be observed: the chip length of Fraction B first increases and then decreases at $\gamma_{o}=5^{\circ}$, the chip length of Fraction B decreases at $\gamma_{o}=30^{\circ}$, the chip length of Fraction $\mathrm{C}$ increases at $\gamma_{o}=5^{\circ}$,

- on changing $v_{c}$, the chip width $\mathrm{S}$ of intermediate Fraction B first increases and then decreases at $\gamma_{o}$ $=5^{\circ}$ and decreases at $\gamma_{o}=30^{\circ}$,
- on changing $f_{z}$, in intermediate chip Fraction B $\left(\gamma_{o}\right.$ $=5^{\circ}$ and $\gamma_{o}=30^{\circ}$ ), intermediate chip Fraction $\mathrm{C}$ $\left(\gamma_{o}=5^{\circ}\right)$, the following trends can be observed: the chip width B of Fraction B first increases and then decreases at $\gamma_{o}=5^{\circ}$, and decreases at $\gamma_{o}=$ $30^{\circ}$, while the chip width of Fraction $\mathrm{C}$ increases at $\gamma_{o}=5^{\circ}$,

- on changing $v_{c}$, the surface area $\mathrm{P}$ of intermediate Fraction $\mathrm{B}$ first increases and then decreases at $\gamma_{o}$ $=5^{\circ}$ and decreases at $\gamma_{o}=30^{\circ}$,

- on changing $f_{z}$, in intermediate chip Fractions B $\left(\gamma_{o}=5^{\circ}\right.$ and $\left.\gamma_{o}=30^{\circ}\right)$ and intermediate Fraction $\mathrm{C}\left(\gamma_{o}=5^{\circ}\right)$ the following trends can be observed: the surface area of chip Fraction B first increases and then decreases at $\gamma_{o}=5^{\circ}$, the surface area of 


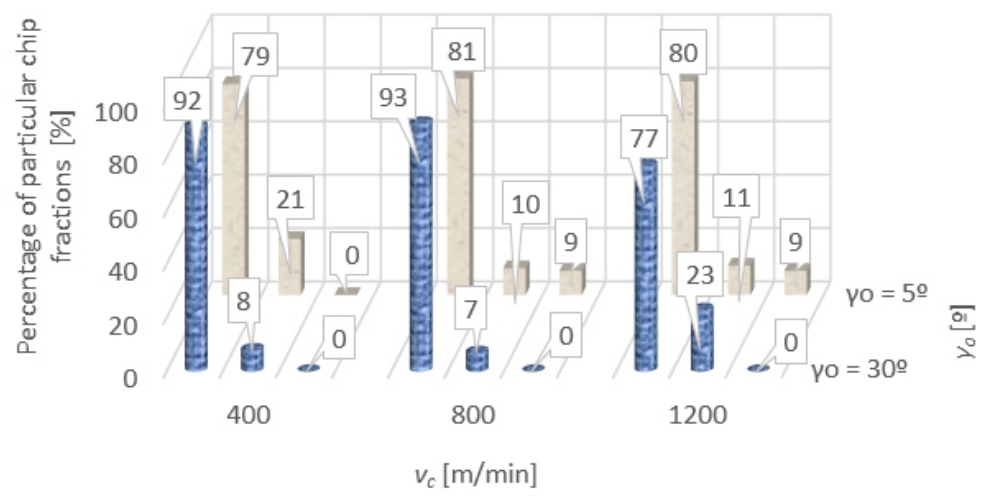

Fig. 15. Chip fraction percentage versus rake angle $\gamma_{o}$ and cutting speed $v_{c}$

Fraction B decreases at $\gamma_{o}=30^{\circ}$, the surface area of Fraction C increases at $\gamma_{o}=5^{\circ}$.

The analysed changes in the technological parameters of milling included the cutting speed $v_{c}$ and the feed per tooth $f_{z}$. The tests investigated the impact of the aforementioned parameters and the rake value $\gamma_{o}$ on the quantity of chip fractions generated during the milling of AZ91HP magnesium alloy. It was found that it is possible to determine the desired milling conditions to ensure control of the number of chip fractions. The conducted tests allowed us to formulate recommendations for effective and safe milling of AZ91HP magnesium alloy with respect to chip ignition hazard.

The experimental results about the degree of chip fragmentation indicate that fewer fractions were generated at the rake angle $\gamma_{o}=30^{\circ}$.

On balance, the most beneficial milling conditions are ensured at the cutting speed $v_{c}=800 \mathrm{~m} / \mathrm{min}$ and $v_{c}=1200 \mathrm{~m} / \mathrm{min}$, the feed tooth values of $f_{z}=0.15$ $\mathrm{mm} /$ tooth and $f_{z}=0.3 \mathrm{~mm} /$ tooth and the depth of cut of $a_{p}=6 \mathrm{~mm}$.

Regarding machining safety (including ignition risk), it is desirable to have the largest share of chip fractions. Additionally, Fig. 15 illustrates the relationship between the chip fraction share in total percentage depending on the applied rake angle and cutting speed.

It can be observed that increasing the rake angle and cutting speed leads to a decrease in the quantity of chips in the leading fraction, particularly at $\gamma_{o}=30^{\circ}$. In contrast, the quantity of chips in the intermediate Fraction B increases. This observation is vital for process safety and effectiveness of the cutting process. It is therefore recommended, due to the fragmentation of chips, to use tools with a smaller rake angle $\left(\gamma_{o}=\right.$ $5^{\circ}$ ), particularly in higher cutting speed ranges that are typical of HSM processes.

\section{CONCLUSIONS}

Based on the experimental observations, the authors have formulated the following conclusions:

I. fewer chip fractions (less fragmentation) are generated at the tool rake angle $\gamma_{o}=30^{\circ}$.

II. The most advantageous chip in terms of removal from the milling machine working space and storage is formed at the following parameters: depth of cut $a_{p}=6 \mathrm{~mm}$, feed per tooth $f_{z}=0.05$ $\mathrm{mm} /$ tooth and $f_{z}=0.15 \mathrm{~mm} /$ tooth, cutting speed $v_{c}=400 \mathrm{~m} / \mathrm{min}$ and $v_{c}=800 \mathrm{~m} / \mathrm{min}$.

III. The results demonstrate that the biggest possible depth of cut and feed per tooth should be applied provided that quality requirements are adhered to. This observation is confirmed by the analysis of formed chip fractions.

IV. It is impossible to state unequivocally whether chip dimensions increase or decrease with increasing the values of technological parameters $\left(v_{c}\right.$ and $\left.f_{z}\right)$.

V. The variations in chip dimensions are directly connected with decohesion (separation) of the machined layer into machining effects in the form of individual leading and intermediate chip fractions.

\section{NOMENCLATURE}

$v_{c} \quad$ cutting speed, $[\mathrm{m} / \mathrm{min}]$

$n$ rotational speed, [rev/min]

$f_{z} \quad$ feed per tooth, [mm/tooth]

$a_{p}$ axial depth of cut, [mm]

$a_{e}$ radial depth of cut, [mm]

$\gamma_{o}$ rake angle (in plane $P_{o}$ ), $\left[^{\circ}\right]$

$\mathrm{L}$ length of chip, $[\mu \mathrm{m}]$

$\mathrm{S}$ width of chip, $[\mu \mathrm{m}]$

P surface area of chip, $\left[\mu \mathrm{m}^{2}\right]$ 


\section{REFERENCES}

[1] Wang, L., Zhou, J., Liang, J., Chen, J. (2013). Thermal control coatings on magnesium alloys prepared by plasma electrolytic oxidation. Applied Surface Science, 280, p. 151-155, DOI:10.1016/J.apsusc.2013.04.115.

[2] Rashid, R.A.R., Sun, S., Wang, G., Dargusch M.S. (2013). Experimental investigation of laser assisted machining of AZ91 magnesium alloy. International Journal of Precision Engineering and Manufacturing, vol. 14, no. 7, p. 1263-1265, DOI:10.1007/s12541-013-0172-1.

[3] Bagheri, H.R., Aliofkhazraei, M., Gheytani, M., Masiha, H.R., Sabour Rouhaghdam, A., Shahrabi, T. (2015). Growth and internal microstructure of micro-arc oxidized Mg0-based nanocomposite coating. Surface and Coatings Technology, vol. 283, p. 1-9, D0l:10.1016/j.surfcoat.2015.10.041.

[4] Wang, J., Liu, Y.B., An, J., Wang, L.M. (2008). Wear mechanism map of uncoated HSS tools during drilling die-cast magnesium alloy. Wear, vol. 265, no. 5-6, p. 685-691, D0l:10.1016/j. wear.2007.12.009.

[5] Carou, D., Rubio, E.M., Lauro, C.H., Davim, J.P. (2014). Experimental investigation on finish intermittent turning of UNS M11917 magnesium alloy under dry machining. The International Journal of Advanced Manufacturing Technology, vol. 75 , no. 9-12, p. 1417-1429, D0l:10.1007/s00170-0146215-7.

[6] Weinert, K., Inasaki, I., Sutherland, J.W., Wakabayashi, T. (2004). Dry machining and minimum quantity lubrication. CIRP Annals - Manufacturing Technology, vol. 53, no. 2, p. 511-537, D0l:10.1016/S0007-8506(07)60027-4.

[7] Tomac, N., Tonnessen, K., Rasch, F.O. (1991). Formation of flank build-up in cutting magnesium alloys. CIRP Annals - Manufacturing Technology, vol. 40, no. 1, p. 79-82, DOI:10.1016/S0007-8506(07)61938-6.

[8] Kulekci, M.K. (2008). Magnesium and its alloys applications in automotive industry. The International Journal of Advanced Manufacturing Technology, vol. 39, no. 9-10, p. 851-865, D0I:10.1007/s00170-007-1279-2.

[9] Shi, K., Zhang, D., Ren, J. (2015). Optimization of process parameters for surface roughness and microhardness in dry milling of magnesium alloy using Taguchi with grey relational analysis. The International Journal of Advanced Manufacturing Technology, vol. 81, no. 1-4, p. 645-651, D0l:10.1007/s00170015-7218-8.

[10] Hou, J., Zhao, N., Zhu, S. (2011). Influence of cutting speed on flank temperature during face milling of magnesium alloy. Materials and Manufacturing Processes, vol. 26, no. 8, p. 1059-1063, DOI:10.1080/10426914.2010.536927.

[11] Oczoś, K.E. (2009). Extension of the magnesium alloys application range. Mechanik, 5-6, p. 386-400, http://www. mechanik.media.pl/archiwum,2009,50.html (in Polish)

[12] Wojciechowski, S., Twardowski, P., Pelic, M., Maruda, R.W., Barrans, S., Krolczyk, G.M. (2016). Precision surface characterization for finish cylindrical milling with dynamic tool displacements model. Precision Engineering, vol. 46, p. 158165, D0I:10.1016/j.precisioneng.2016.04.010.

[13] Wojciechowski, S., Maruda, R.W., Nieslony, P., Krolczyk, G.M. (2016). Investigation on the edge forces in ball end milling of hardened steel. International Journal of Mechanical Sciences, vol. 119, p. 360- 369, D0l:10.1016/j.ijmecsci.2016.10.034.

[14] Maruda, R.W., Krolczyk, G.M., Nieslony, P., Wojciechowski, S., Michalski, M., Legutko, S. (2016). The influence of the cooling conditions on the cutting tool wear and the chip formation mechanism. Journal of Manufacturing Processes, vol. 24, p. 107-115, DOI:10.1016/J.jmapro.2016.08.006.

[15] Gziut, O., Kuczmaszewski, J., Zagórski, I. (2016). Surface quality assessment following high performance cutting of AZ91HP magnesium alloy. Management and Production Engineering Review, vol. 6, no. 1, p. 4-9, Dol:10.1515/mper2015-0001.

[16] Józwik, J., Mika, D. (2015). Diagnostics of workpiece surface condition based on cutting tool vibrations during machining. Advances in Science and Technology Research Journal, vol. 9, no. 26, p. 57-65, Dol:10.12913/22998624/2365.

[17] Guo, Y.B., Salahshoor, M. (2010). Process mechanics and surface integrity by high-speed dry milling of biodegradable magnesium-calcium implant alloys. CIRP Annals Manufacturing Technology, vol. 59, no. 1, p. 151-154, D0I:10.1016/j.cirp.2010.03.051.

[18] Ruggiero, A., D’Amato, R., Gómez, E., Merola, M. (2016). Experimental comparisonon tribological pairs UHMWPE/ TIAL6V4 alloy, UHMWPE/AISI316L austenitic stainless and UHMWPE/AL203 ceramic, under dry and lubricated conditions. Tribology International, vol. 96, p. 349-360, D0I:10.1016/j.triboint.2015.12.041.

[19] Ruggiero, A., D’Amato, R., Gómez, E. (2015). Experimental analysis of tribological behavior of UHMWPE against AISI420C and against TiAl6V4 alloy under dry and lubricated conditions. Tribology International, vol. 92, 154-161, D0l:10.1016/j. triboint.2015.06.005.

[20] Li, H.Z., Liu, K., Li., X.P. (2001). A new method for determining the undeformed chip thickness in milling. Journal of Materials Processing Technology, vol. 113, no. 1-3, p. 378-384, DOl:10.1016/S0924-0136(01)00586-6.

[21] Saï, L., Bouzid, W., Zghal, A. (2008). Chip thickness analysis for different tool motions: for adaptive feed rate. Journal of Materials Processing Technology, vol. 204, no. 1-3, p. 213220, D0I:10.1016/j.jmatprotec.2007.11.094.

[22] Fang, F.Z., Lee, L.C., Liu, X.D. (2005). Mean flank temperature measurement in high speed dry cutting. Journal of Materials Processing Technology, vol. 167, no. 1, p. 119-123, DOl:10.1016/j.jmatprotec.2004.10.002.

[23] Hou, J.Z., Zhou, W., Zhao, N. (2010). Methods for prevention of ignition during machining of magnesium alloys. Key Engineering Materials, vol. 447-448, p. 150-154, D0I:10.4028/www.scientific.net/KEM.447-448.150.

[24] Zhao, N., Hou, J., Zhu, S. (2011). Chip ignition in research on high-speed face milling AM50A magnesium alloy. $2^{\text {nd }}$ International Conference on Mechanic Automation and Control Engineering, no. 5987127, p. 1102-1105, DOI:10.1109/MACE.2011.5987127.

[25] Hou, J.Z., Zhou, W., Zhao, N. (2010). Effect of cutting parameters on ignition of AM50A mg alloy during face milling. Materials and Manufacturing Processes, vol. 25, no. 10, p. 1048-1051, D0I:10.1080/10426910903496870. 
[26] Akyuz, B. (2011). Machinability of magnesium and its alloys. The Online Journal of Science and Technology, vol. 1, no. 3, p. 31-38.

[27] Lin, P.Y., Zhou, H., Li, W., Li, W.P., Sun., N., Yang, R. (2008). Interactive effect of cerium and aluminium on the ignition point and the oxidation resistance of magnesium alloy. Corrosion Science, vol. 50, no. 9, p. 2669-2675, Dol:10.1016/j. corsci.2008.06.025.

[28] Zhou, H., Li, W., Wang, M., Zhao, Y. (2005). Study of ignition proof AZ91D magnesium alloy chips with cerium addition. Journal of Rare Earths, vol. 23, p. 466-469, available from https://www.researchgate.net/publication/279539824_ Study_on_ignition_proof_AZ91D_magnesium_alloy_chips_ with_cerium_addition accessed on 2017-02-21.

[29] Liu, M., Shih, D.S., Parish, C., Atrens, A. (2012). The ignition temperature of Mg alloys WE43, AZ31 and AZ91. Corrosion Science, vol. 54, p. 139-142, D0I:10.1016/j. corsci.2011.09.004.
[30] Ravi Kumar, N.V., Blandin, J.J., Suéry, M., Grosjean, E. (2003). Effect of alloying elements on the ignition resistance of magnesium alloys. Scripta Materialia, vol. 49, no. 3, p. 225230, DOI:10.1016/S1359-6462(03)00263-X.

[31] ISO 3685:1993. Tool-life testing with single-point turning tools. International Organization for Standardization, Geneva

[32] Kuczmaszewski, J., Zagórski, I. (2014). Investigation of chips fragmentation during magnesium alloys milling. Mechanik, 8-9, p. 321-328, from http://www.mechanik.media.pl/pliki/ do_pobrania/artykuly/13/viii_sos.pdf, accessed on 2017-0221. (in Polish)

[33] Salahshoor, M., Guo, Y.B. (2011). Surface integrity of magnesium-calcium implants processed by synergistic dry cutting-finish burnishing. Procedia Engineering, vol. 19, p. 288-293, D0I:10.1016/j.proeng.2011.11.114.

[34] Matuszak, J., Zaleski, K. (2014). Edge states after wire brushing of magnesium alloys. Aircraft Engineering and Aerospace Technology, vol. 86, no. 4, p. 328-335, DOI:10.1108/AEAT-09-2012-0155. 